\title{
EFLUENTES HOSPITALARIOS COMO RESERVORIO DE ENTEROBACTERIAS PRODUCTORAS DE BETALACTAMASAS Y CARBAPENEMASAS
}

\author{
David R. Soriano-Moreno (1D) 1,a José Yareta (1) 1,c , Ana F. Rojas-Cosi(iD), \\ Alexander Fajardo-Loyola (iD,b, Diana León-Luna (iD), ,Isabel Castillo-Quezada(i) 1,a, \\ Mario Laura-Bejarano (D1,a, Milagros Hilario-Sánchez (iD),a, Marco Galarza-Pérez (iD),c, \\ Pool Marcos-Carbajal (D1,d \\ 1 Laboratorio de Investigación en Biología Molecular, Escuela Profesional de Medicina Humana, Universidad Peruana \\ Unión (UPeU), Lima, Perú. \\ 2 Facultad de Ciencias Naturales y Matemática, Universidad Nacional Federico Villarreal, Lima, Perú.

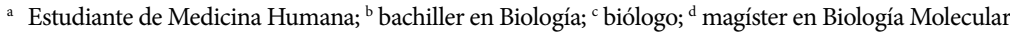

\section{RESUMEN}

Con el objetivo de determinar la presencia de enterobacterias productoras de betalactamasas (bla) en muestras de efluentes hospitalarios, se realizó un estudio en dos hospitales de nivel II y III de Lima, Perú. Se identificó y caracterizó el perfil de resistencia de las bacterias aisladas mediante el sistema MicroScan para 18 antimicrobianos, y mediante PCR convencional se determinó la presencia de los genes de resistencia a betalactamasas de espectro de extendido (BLEE) $\left(b l a_{\mathrm{CTX}-\mathrm{M}}, b l a_{\mathrm{SHV}}, b l a_{\mathrm{TEM}}, b l a_{\mathrm{PER}}\right)$ y carbapenemasas $\left(b l a_{\mathrm{KPC}}, b l a_{\mathrm{NDM}}, b l a_{\mathrm{VIM}}, b l a_{\mathrm{IMP}}\right)$. Se identificaron 32 aislados (20 enterobacterias y 12 bacterias gramnegativas). Todas las bacterias aisladas presentaron multirresistencia. Se halló la presencia de genes BLEE $\left(b l a_{\mathrm{TEM}}\right)$ y carbapenemasas $\left(b l a_{\mathrm{KPC}}\right.$ y $\left.b l a_{\mathrm{IMP}}\right)$ en los hospitales evaluados. La liberación de estos microorganismos a la vía pública y la falta de tratamiento de los efluentes hospitalarios podría ser un importante problema de salud pública.

Palabras claves: Resistencia Bacteriana; Farmacorresistencia Bacteriana Múltiple; Antimicrobianos; Aguas Residuales; Alcantarillado; Salud Pública; Hospitales públicos; Perú (Fuente: DeCS BIREME).

\section{HOSPITAL EFFLUENTS AS A RESERVOIR OF BETA- LACTAMASE- AND CARBAPENEMASE-PRODUCING ENTEROBACTERIACEAE}

Citar como: Soriano-Moreno DR, Yareta J, Rojas-Cosi AF, Fajardo-Loyola A, León-Luna D, Castillo-Quezada I, et al. Efluentes hospitalarios como reservorio de enterobacterias productoras de betalactamasas y carbapenemasas. Rev Peru Med Exp Salud Publica. 2021;38(2):302-7. doi: https://doi. org/10.17843/rpmesp.2021.382.6202.

Correspondencia:José Luis Yareta Yareta; Urb. Alameda de Ñaña I Etapa Mz. D Lte. 11, Lurigancho, Lima, Perú; joseyareta@upeu.edu.pe

Recibido: 04/08/2020 Aprobado: 17/03/2021 En línea: 13/04/2021

\begin{abstract}
The aim of this study was to determine the presence of beta-lactamase- (bla) producing Enterobacteriaceae in hospital effluent samples from two level II and III hospitals in Lima, Peru. The resistance profile of the isolated bacteria was identified and characterized using the MicroScan system for 18 antimicrobials, and the presence of extended spectrum beta-lactamases (ESBL) ( $\mathrm{bla}_{\mathrm{CTX}-\mathrm{M}}, b l a_{\mathrm{SHV}} b l a_{\mathrm{TEM}}, b l a_{\mathrm{PER}}$ ) and carbapenemases $\left(b l a_{\mathrm{KPC}}, b l a_{\mathrm{NDM}}, b l a_{\mathrm{VIM}}, b l a_{\mathrm{IMP}}\right)$ resistance genes was determined by conventional PCR. Thirty-two isolates were identified (20 Enterobacteriaceae and 12 gram-negative bacteria). All the isolated bacteria showed multidrug resistance. ESBL $\left(b l a_{\mathrm{TEM}}\right)$ and carbapenemase (blaKPC, blaIMP) genes were found in samples from the hospitals that we evaluated. The release of these microorganisms to public areas and the lack of treatment of the hospital effluents could be an important public health problem.
\end{abstract}

Keywords: Antibacterial Drug Resistance; Multiple Antibacterial Drug Resistance; Antibacterial Agents; Waste Water; Sewerage; Public Health; Public Hospitals; Peru (Source: MeSH NLM).

\section{INTRODUCCIÓN}

La multirresistencia bacteriana es un problema de salud, debido a la alta mortalidad relacionada a su exposición y a la falta de opciones terapéuticas ${ }^{(1)}$. Estudios previos han demostrado que los efluentes hospitalarios contienen antibióticos y bacterias multirresistentes ${ }^{(2,3)}$, especialmente las enterobacterias que son productoras de betalactamasas con capacidad de hidrolizar penicilinas, cefalosporinas, monobactámicos, carbapenemes e inhibidores de betalactamasas ${ }^{(4)}$. En 
ese sentido, los efluentes hospitalarios son un gran reservorio de bacterias con resistencia a los antimicrobianos.

A diferencia de otros países, donde los efluentes hospitalarios tienen un tratamiento especializado ${ }^{(5)}$, en el Perú solo cinco centros hospitalarios tienen tratamiento de sus residuos sólidos, mas no de líquidos ${ }^{(6)}$. Por lo general, los efluentes hospitalarios desembocan directamente en ríos cercanos en donde las personas se contaminan al utilizar estas aguas para lavar su ropa o para su aseo personal ${ }^{(7)}$.

Por tal motivo, el objetivo de esta investigación fue determinar la presencia de bacterias productoras de betalactamasas de espectro extendido (BLEE) y carbapenemasas en los efluentes hospitalarios de dos hospitales de Lima y caracterizar su perfil de resistencia, a fin de generar evidencia que sirva para tomar medidas de control y bioseguridad.

\section{EL ESTUDIO}

El estudio fue de tipo transversal descriptivo y se realizó en el Laboratorio de Investigación en Biología Molecular de la Universidad Peruana Unión (LIBM-UPeU). Las muestras de los efluentes hospitalarios se obtuvieron de dos hospitales de Lima. El Hospital de Huaycán de nivel II, ubicado en el distrito de Ate cuenta con servicios de emergencia y hospitalización y atiende alrededor de 647000 personas ${ }^{(8)}$. El Hospital Hipólito Unanue de nivel III ubicado en el distrito de El Agustino cuenta con los servicios de consulta externa, emergencia, hospitalización y centro quirúrgico; y durante el 2018 se han realizado alrededor de 200000 atenciones médicas ${ }^{(9)}$.

Se recolectaron muestras de efluentes de aguas residuales antes de su vertimiento al sistema de alcantarillado, durante los meses de junio y julio del 2019. Se obtuvieron dos muestras en frascos estériles de $100 \mathrm{ml}$ por cada hospital con una diferencia de 30 minutos entre ambas tomas en un mismo punto. Posteriormente, fueron transportadas en cadena fría $\left(2-8{ }^{\circ} \mathrm{C}\right)$ hasta el laboratorio. Las muestras recolectadas fueron diluidas con agua destilada (dilución 1:50) y se inoculó $1 \mathrm{ml}$ por triplicado en medios selectivos para bacterias con fenotipo resistentes a penicilinas, cefalosporinas de amplio espectro de tercera generación y monobactámicos (medio, CHROMagar ESBL) y en medios selectivos para bacterias con fenotipo resistentes a carbapenemasas (medio, CHROMagar mSupercarba), según las instrucciones del fabricante ${ }^{(10)}$. Luego, se resembraron las colonias en agar MacConkey, cuatro cepas por placa y se dejó incubar a $37^{\circ} \mathrm{C}$ por 24 horas. Esto se realizó con la finalidad de aislar las colonias y realizar su respectiva identificación.

La identificación y perfil de susceptibilidad se realizó mediante el uso del sistema automatizado MicroScan ${ }^{\circ}$ (AutoScan-4) y el uso de paneles para bacterias gramnegativas

\section{MENSAJES CLAVE}

Motivación para realizar el estudio: La falta de tratamiento de los efluentes hospitalarios con antibióticos y con bacterias multirresistentes podría ser un problema de salud pública.

Principales hallazgos: Las enterobacterias y bacterias gramnegativas aisladas presentaron multirresistencia. Se halló la presencia de genes BLEE $\left(b l a_{\mathrm{TEM}}\right)$ y carbapenemasas $\left(b l a_{\mathrm{KPC}}\right.$ e $\left.b l a_{\mathrm{IMP}}\right)$ en los efluentes de hospitales de nivel II y III de Lima.

Implicancias: La alta presencia de enterobacterias y bacterias gramnegativas multirresistentes productoras de genes $b l a_{\mathrm{TEM}}$, $b l a_{\mathrm{KPC}}$ y $b l a_{\mathrm{IMP}}$ en los efluentes hospitalarios es alarmante y debe llevar a implementar sistemas de tratamiento de las aguas residuales antes de ser vertidas al sistema de alcantarillado.

$\left(\right.$ Dade MicroScan $\left.^{\circ}\right)$, siguiendo indicaciones del fabricante ${ }^{(10)}$. Se utilizaron 18 antimicrobianos para cada cepa. Los valores de la concentración mínima inhibitoria (CMI) fueron utilizados para interpretar el perfil de resistencia antibiótica según los puntos de corte recomendados por la Clinical and Laboratory Standards Institute $2020^{(11)}$. La multirresistencia fue definida según la detección de un fenotipo resistente, al menos, a un antimicrobiano en tres o más familias ${ }^{(12)}$.

La extracción del ADN se realizó por el método basado en columnas de silicagel específico para bacterias con el kit innuPREP Bacteria DNA (Analytikjena, Alemania), siguiendo el protocolo de fabricante ${ }^{(13)}$. El ADN aislado se almacenó a $-20^{\circ} \mathrm{C}$ hasta la amplificación de cada gen por PCR convencional. Para la detección de genes BLEE $\left(b l a_{\mathrm{CTX}-\mathrm{M}}, b l a_{\mathrm{SHV}}, b l a_{\mathrm{TEM}}, b l a_{\mathrm{PER}}\right) \mathrm{y}$ carbapenemasas $\left(b l a_{\mathrm{KPC}}, b l a_{\mathrm{NDM}}, b l a_{\mathrm{VIM}}, b l a_{\mathrm{IMP}}\right)$ se utilizó la PCR convencional, en un termociclador de punto final (Bio-Rad, EUA) ${ }^{(14,15)}$. Los cebadores utilizados para este fin se detallan en el Tabla 1. Los productos de amplificación se visualizaron por electroforesis en geles de agarosa al $2 \%$ a 120v por 55 minutos, según protocolo estandarizado en el LIBM-UPeU.

Los resultados se procesaron con el software Labpro y se exportaron al programa Microsoft Excel en donde posteriormente se analizaron. Se obtuvo el número de aislados identificados según hospital. Se elaboró un mapa de calor con el perfil de resistencia antibiótica de las bacterias aisladas para cada hospital y el perfil de genes bla ${ }^{(11)}$.

El estudio se clasificó como una investigación sin riesgo y no requirió consentimiento informado. El manejo de los datos se realizó con estrictos parámetros de confidencialidad. Esta investigación fue evaluada y aprobada por el Comité de Ética de la Universidad Peruana Unión. 
Tabla 1. Cebadores utilizados para la detección de genes de resistencia BLEE y carbapenemasas.

\begin{tabular}{|c|c|c|c|}
\hline Genes & $\begin{array}{c}\text { Amplicón } \\
(\mathrm{pb})\end{array}$ & Cebador & Secuencia \\
\hline$b l a_{\mathrm{CTX}-\mathrm{M}}^{(14)}$ & 544 & $\begin{array}{l}\mathrm{CTX} / \mathrm{F} \\
\mathrm{CTX} / \mathrm{R}\end{array}$ & $\begin{array}{l}\text { TTTGCGATGTGCAGTACCAGTAA } \\
\text { CGATATCGTTGGTGGTGCCAT }\end{array}$ \\
\hline$b l a_{\mathrm{TEM}}{ }^{(14)}$ & 931 & $\begin{array}{l}\mathrm{TEM} / \mathrm{F} \\
\mathrm{TEM} / \mathrm{R}\end{array}$ & $\begin{array}{l}\text { TCCGCTCATGAGACAATAACC } \\
\text { TTGGTCTGACAGTTACCAATGC }\end{array}$ \\
\hline$b l a_{\mathrm{SHV}}{ }^{(14)}$ & 868 & $\begin{array}{l}\text { SHV/F } \\
\text { SHV/R }\end{array}$ & $\begin{array}{l}\text { TGGTTATGCGTTATATTCGCC } \\
\text { GGTTAGCGTTGCCAGTGCT }\end{array}$ \\
\hline$b l a_{\mathrm{PER}}{ }^{(14)}$ & 927 & $\begin{array}{l}\mathrm{PER} / \mathrm{F} \\
\mathrm{PER} / \mathrm{R}\end{array}$ & $\begin{array}{l}\text { ATGAATGTCATCACAAAATG } \\
\text { TCAATCCGGACTCACT }\end{array}$ \\
\hline$b l a_{\mathrm{KPC}}{ }^{(15)}$ & 916 & $\begin{array}{l}\mathrm{KPC} / \mathrm{F} \\
\mathrm{KPC} / \mathrm{R}\end{array}$ & $\begin{array}{l}\text { AACAAGGAATATCGTTGATG } \\
\text { AGATGATTTTCAGAGCCTTA }\end{array}$ \\
\hline$b l a_{\mathrm{NDM}}{ }^{(15)}$ & 512 & $\begin{array}{l}\mathrm{NDM} / \mathrm{F} \\
\mathrm{NDM} / \mathrm{R}\end{array}$ & $\begin{array}{l}\text { AGCACACTTCCTATCTCGAC } \\
\text { GGCGTAGTGCTCAGTGTC }\end{array}$ \\
\hline$b l a_{\mathrm{VIM}}{ }^{(15)}$ & 261 & $\begin{array}{l}\mathrm{VIM} / \mathrm{F} \\
\mathrm{VIM} / \mathrm{R}\end{array}$ & $\begin{array}{l}\text { AGTGGTGAGTATCCGACAG } \\
\text { ATGAAAGTGCGTGGAGAC }\end{array}$ \\
\hline$b l a_{\mathrm{IMP}}{ }^{(15)}$ & 404 & $\begin{array}{l}\mathrm{IMP} / \mathrm{F} \\
\mathrm{IMP} / \mathrm{R}\end{array}$ & $\begin{array}{l}\text { GGYGTTTWTGTTCATACWTCKTTYGA } \\
\text { GGYARCCAAACCACTASGTTATCT }\end{array}$ \\
\hline
\end{tabular}

F: Forward, R: Reverse; CTX-M: cefotaximasas; TEM: temoniera; SHV: sulfhidrilo variable; KPC: Klebsiella pneumoniae carbapenemasa; NDM: New Delhi metalo $\beta$-lactamasa; IMP: Imipenemasa metalo $\beta$-lactamasa; VIM: codificado-integrón Verona metalo $\beta$-lactamasa; pb: pares de bases; bla: genes beta-lactamasas.

\section{HALLAZGOS}

Se aislaron 32 cepas del filo Proteobacteria; en el hospital de nivel II y III se aislaron $14(43,8 \%)$ y $18(56,2 \%)$, respectivamente. En el hospital de nivel II, fueron identificadas 8 $(57,1 \%)$ enterobacterias y $6(42,9 \%)$ bacterias gramnegativas; y en el hospital de nivel III fueron identificadas $12(66,7 \%)$ enterobacterias y $6(33,3 \%)$ bacterias gramnegativas (Tabla 2$)$. En total se identificaron $20(62,5 \%)$ enterobacterias; las más frecuentes fueron Enterobacter cloacae (6/20;30\%), Escherichia coli $(5 / 20 ; 25 \%)$ y Citrobacter freundii complex (4/20; $20 \%)$.

Con respecto al fenotipo de resistencia, el $100 \%$ de los aislados de ambos hospitales presentó multirresistencia, incluyendo resistencia a betalactámicos, ciprofloxacino, trimetoprima/sulfametoxazol, eritromicina, tigeciclina y una Pseudomonas aeruginosa resistente a la amikacina (Figura 1). El perfil de resistencia antibiótica en enterobacterias (8/20) aisladas del hospital de nivel II fue amikacina (0,0\%), ácido clavulánico (37,5\%), ampicilina/sulbactam (62,5\%), ampicilina $(100,0 \%)$, aztreonam $(100,0 \%)$, cefepima $(87,5 \%)$, cefotaxima $(100,0 \%)$, ceftazidima $(87,5 \%)$, cefuroxima $(100,0 \%)$, ciprofloxacina $(87,5 \%)$, eritromicina $(50,0 \%)$, gentamicina $(37,5 \%)$, imipenem $(12,5 \%)$, meropenem $(3,1 \%)$, piperacilina/tazobactam $(9,4 \%)$, tigeciclina $(0,0 \%)$, tobramicina $(15,6 \%)$, trimetoprima/sulfametoxazol $(9,4 \%)$.
Tabla 2. Número y frecuencia de especies aisladas en efluentes de dos hospitales de Lima, según nivel de atención.

\begin{tabular}{|c|c|c|c|c|}
\hline \multirow[t]{2}{*}{ Especies bacterianas $(n=32)$} & \multicolumn{2}{|c|}{$\begin{array}{c}\text { Hospital } \\
\text { de nivel II }\end{array}$} & \multicolumn{2}{|c|}{$\begin{array}{c}\text { Hospital } \\
\text { de nivel III }\end{array}$} \\
\hline & $n=14$ & $\%$ & $\mathrm{n}=18$ & $\%$ \\
\hline Enterobacterias & 8 & 57,1 & 12 & 66,7 \\
\hline Citrobacter freundii complex & 3 & 21,4 & 1 & 5,6 \\
\hline Enterobacter cloacae & SA & 0,0 & 6 & 33,3 \\
\hline Enterobacter asburiae & 1 & 7,1 & SA & 0,0 \\
\hline Escherichia coli & 3 & 21,4 & 2 & 11,1 \\
\hline Escherichia vulneris & SA & 0,0 & 1 & 5,6 \\
\hline Klebsiella oxytoca & 1 & 7,1 & 2 & 11,1 \\
\hline Gramnegativos & 6 & 42,9 & 6 & 33,3 \\
\hline Achromobacter xylosoxidans & SA & 0,0 & 1 & 5,6 \\
\hline Aeromonas hydrophila & 1 & 7,1 & SA & 0,0 \\
\hline Pseudomonas aeruginosa & 1 & 7,1 & 1 & 5,6 \\
\hline Pseudomonas spp. & 1 & 7,1 & SA & 0,0 \\
\hline Vibrio fluvialis & 2 & 14,3 & 3 & 16,7 \\
\hline Yersinia enterocolitica & 1 & 7,1 & 1 & 5,6 \\
\hline
\end{tabular}

SA: sin aislado bacteriano.

Mientras que el perfil de resistencia antibiótica en enterobacterias (12/20) del hospital de nivel III fue: amikacina $(0,0 \%)$, ácido clavulánico $(91,7 \%)$, ampicilina/sulbactam (91,7\%), ampicilina (100,0\%), aztreonam (100,0\%), cefepima $(100,0 \%)$, cefotaxima $(100,0 \%)$, ceftazidima $(100,0 \%)$, cefuroxima $(100,0 \%)$, ciprofloxacina $(41,7 \%)$, eritromicina (66,7\%), gentamicina (41,7\%), imipenem $(41,7 \%)$, meropenem $(21,9 \%)$, piperacilina/tazobactam (15,6\%), tigeciclina $(0,0 \%)$, tobramicina $(6,3 \%)$, trimetoprima/sulfametoxazol $(9,4 \%)$ (Figura 2).

Los genes detectados en el hospital de nivel II fueron en

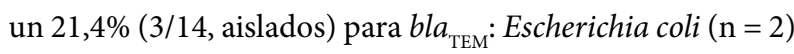
y Klebsiella oxytoca $(\mathrm{n}=1)$; para el gen $b l a_{\mathrm{KPC}}$ en un $28,6 \%$ (4/14, aislados): Citrobacter freundii complex $(\mathrm{n}=2)$, Pseudomonas aeruginosa $(\mathrm{n}=1)$ y Vibrio fluvialis $(\mathrm{n}=1)$; y un $7,1 \%$ (1/14, aislados) para el gen $b a_{\mathrm{IMP}}$ : Pseudomonas spp. Mientras que los genes identificados en el hospital de nivel III fueron en un $38,9 \%\left(7 / 18\right.$, aislados) para bla ${ }_{\mathrm{TEM}}$ : Enterobacter cloacae $(\mathrm{n}=2)$, Pseudomonas aeruginosa $(\mathrm{n}=1)$, Yersinia enterocolitica $(\mathrm{n}=1)$, Klebsiella oxytoca $(\mathrm{n}=1)$, Escherichia coli $(\mathrm{n}=1)$ y Escherichia vulneris $(\mathrm{n}=1)$; para el gen bla $_{\mathrm{KPC}}$ en un 44,4\% (8/18, aislados): Enterobacter cloacae $(\mathrm{n}=4)$, Vibrio fluvialis $(\mathrm{n}=3)$ y Citrobacter freundii complex $(\mathrm{n}=1)$. Del total de aislados productores de BLEE no se detectó la presencia de genes $b l a_{\mathrm{CTX}-\mathrm{M}}, b l a_{\mathrm{SHV}}$ y $b l a_{\mathrm{PER}}$; asimismo, de todos los aislados productores de carbapenemasas tampoco se detectaron los genes $b l a_{\mathrm{NDM}}$ ni $b l a_{\mathrm{VIM}}$ (Figura 1 ). 


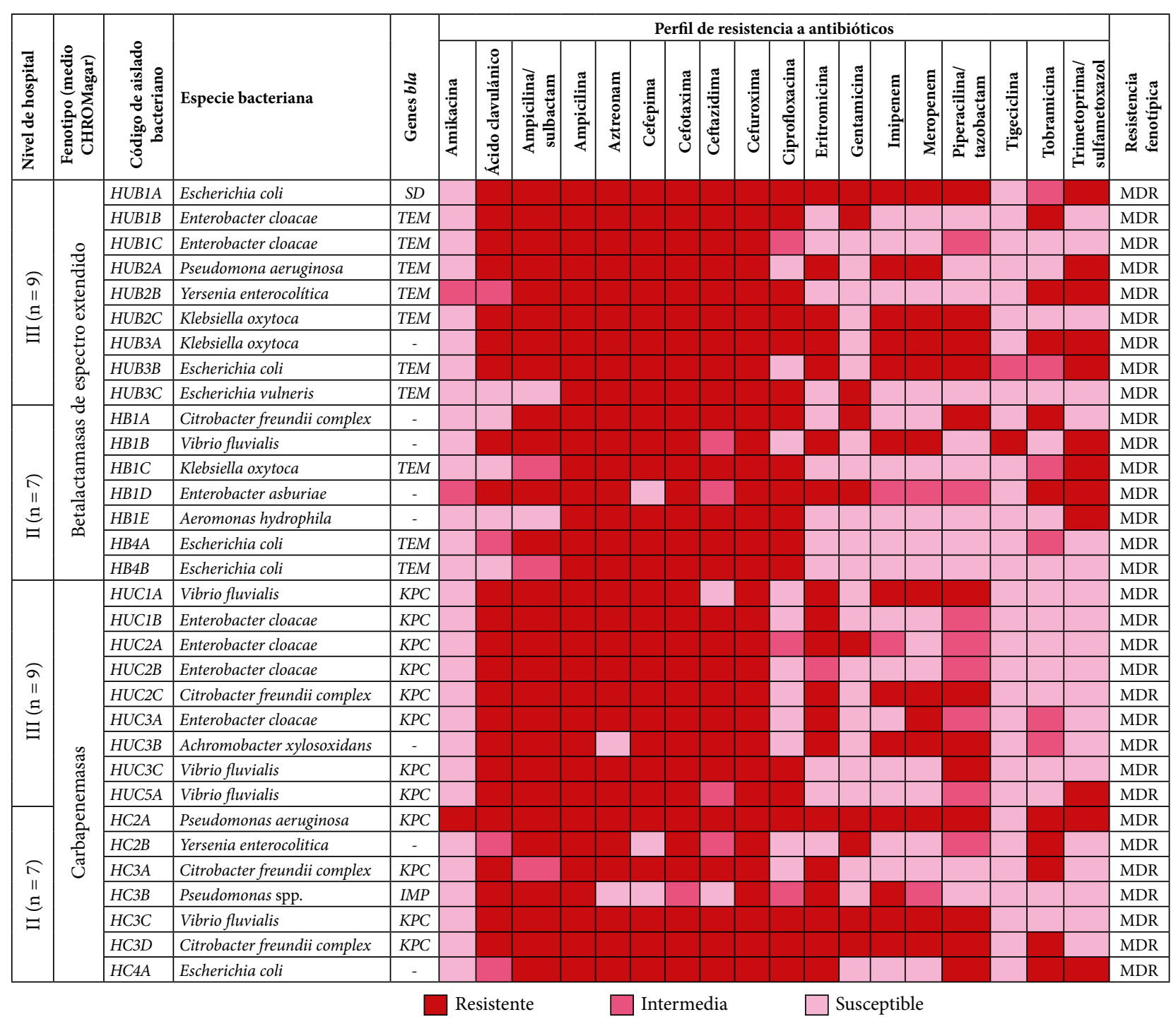

bla: genes betalactamasas, TEM: temoniera, KPC: Klebsiella pneumoniae carbapenemasa, IMP: Imipenemasa metalo $\beta$-lactamasa, MDR: multiresistencia (resistente al menos a un antimicrobiano de 2 o 3 clases de antibióticos), SD: sin detección de genes BLEE o carbapenemasas.

Figura 1. Perfil de resistencia a antibióticos según fenotipo, resistencia fenotípica y genes betalactamasas (BLEE y carbapenemasas) en enterobacterias y bacterias gramnegativas, de dos hospitales de Lima.

\section{DISCUSIÓN}

En el presente estudio, se observó que todas las enterobacterias y bacterias gramnegativas aisladas son multirresistentes. La amikacina y la tigeciclina fueron los antibióticos más sensibles, mientras que el $70 \%$ a $100 \%$ de los aislados fueron resistentes a las ampicilinas, cefalosporinas, monobactámicos y carbapenémicos. Se encontraron genes BLEE $\left(b{ }_{\text {TEM }}\right)$ y carbapenemasas $\left(b a_{\mathrm{KPC}}\right.$ y $\left.b l a_{\mathrm{IMP}}\right)$ en los hospitales nivel II y nivel III, siendo mayor la frecuencia en este último.

Con respecto al perfil de resistencia, todas las enterobacterias y bacterias gramnegativas presentaron resistencia a los antibióticos betalactámicos, con multirresistencia en el 100\% de los aislados. Esto difiere de lo descrito en un hospital de Brasil, en donde la multirresistencia fue del 33,3\%, con un
$38,0 \%$ de resistencia a la cefoxitina; $27,0 \%$ a la ceftazidima; $22,0 \%$ a cefepima, $13,0 \%$ al imipenem, $11,0 \%$ al meropenem y $44,0 \%$ al aztreonam ${ }^{(16)}$. También difiere de otro estudio en China, donde se registró un $85,5 \%$ de multirresistencia, con un $77,4 \%$ de resistencia a la trimetoprima/sulfametoxazol; $66,1 \%$ a la amoxicilina/ácido clavulánico; $61,3 \%$ a la cefoxitina y $61,3 \%$ a la ciprofloxacina ${ }^{(17)}$. Los resultados del presente estudio muestran resistencias mayores, con la excepción de que en el hospital de nivel II se halló solo un 3,1\% de resistencia al meropenem. Una posible explicación sería la carencia de un sistema de tratamiento de residuos líquidos en los hospitales evaluados. Este problema se podría presentar en otros hospitales del Perú, en donde no se tratan los residuos líquidos, lo que podría ser perjudicial para la salud de la población que utiliza las aguas de los ríos para su aseo y para la agricultura. 


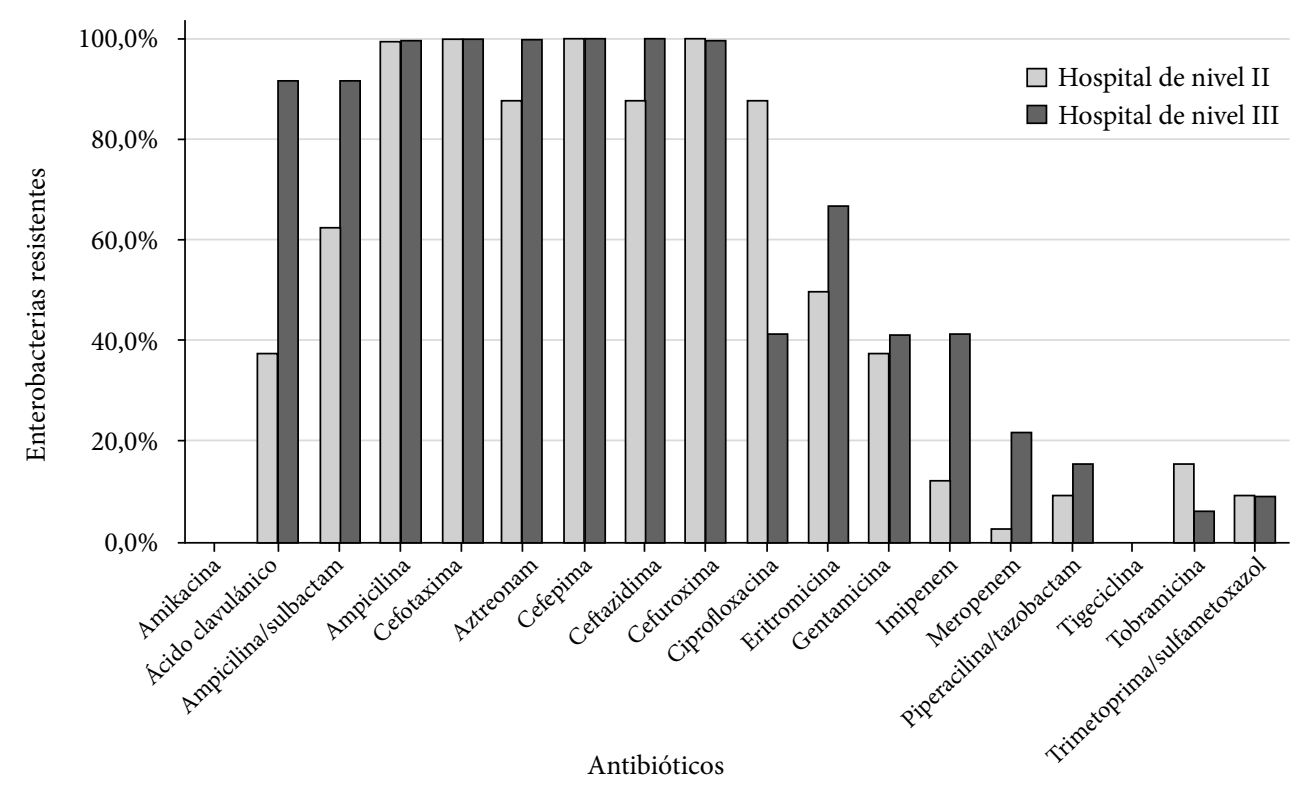

Figura 2. Perfil de resistencia antibiótica en enterobacterias de dos hospitales de Lima, Perú.

Por otro lado, se detectaron genes resistentes a BLEE en un $21,4 \%$ y $38,9 \%$ para los hospitales de nivel II y III, respectivamente, predominando en ambos el gen $b l a_{\text {TEM }}$ en bacterias como Escherichia coli y Klebsiella oxytoca. Asimismo, en un estudio realizado en Brasil se detectó la presencia de genes BLEE en un 35\%, sin embargo, el gen bla ${ }_{\text {Стх }}$ predominó en bacterias como Escherichia coli, Klebsiella pneumoniae y Hafnia alvei. Esta diferencia podría deberse a que los perfiles de susceptibilidad encontrados son distintos cuando hay predominancia del gen $b l a_{\text {СТX }}$, ya que existe resistencia elevada a la gentamicina, trimetoprima/sulfametoxazol y ciprofloxacina, lo que ocurre principalmente por el mecanismo de transmisión de plásmidos en estas bacterias ${ }^{(16)}$. En cuanto a los aislados de genes asociados a carbapenémicos, se detectaron casi en un $28,6 \%$ y $44,4 \%$ para los hospitales de nivel II y III, respectivamente, predominando en ambos el gen $b l a_{\mathrm{KPC}}$. En el estudio reportado en Brasil se detectó también la presencia del gen $b l a_{\mathrm{KPC}}$ asociado a BLEE ${ }^{(16)}$. Por otro lado, en un hospital universitario de Suiza se encontró la presencia del gen $O X A-48$ asociado a Escherichia coli y Citrobacter freundii ${ }^{(18)}$. Sin embargo, en nuestro estudio se resalta la presencia del gen $b l a_{\mathrm{IMP}}$ asociado a Pseudomonas spp.

Se encontró una mayor cantidad de enterobacterias multirresistentes en el hospital de nivel III, lo que podría deberse a la alta demanda de atenciones para una población de más de dos millones de habitantes de los distritos del centro y este de Lima ${ }^{(19)}$. En cambio, el hospital de nivel II que ofrece sus servicios a una población de aproximadamente 200000 habitantes ${ }^{(20)}$, y que tiene menos especialidades, presentó una menor carga de enterobacterias.

Como limitación del estudio se debe mencionar que solo se tuvo acceso a un punto de muestreo de los efluentes hospitalarios, se debió considerar dos puntos de muestreo más, correspondien- tes a puntos donde las aguas residuales urbanas se mezclan con el efluente hospitalario y las aguas residuales urbanas ya mezcladas con los efluentes hospitalarios del alcantarillado público ${ }^{(17)}$. Asimismo, los resultados no podrían ser extrapolables a hospitales de otros niveles de atención y de otras provincias del Perú. Sin embargo, según la revisión realizada, este sería el primer estudio que identifica el fenotipo y los genes de resistencia de enterobacterias provenientes de efluentes de dos hospitales peruanos.

En conclusión, se halló multirresistencia fenotípica en todos los aislados. Asimismo, se encontró una resistencia genotípica a genes BLEE $\left(b l a_{\mathrm{TEM}}\right)$ y carbapenemasas $\left(b l a_{\mathrm{KPC}}\right.$ y $\left.b l a_{\mathrm{IMP}}\right)$, con mayor presencia en el hospital de nivel III. Se recomienda realizar más estudios sobre multirresistencia bacteriana en aguas residuales de efluentes hospitalarios en hospitales de diferentes niveles (I, II, III y IV) del Perú para revelar la calidad microbiológica de los efluentes hospitalarios. Asimismo, se recomienda implementar sistemas de tratamiento de las aguas residuales hospitalarias.

Contribuciones de autoría: PMC concibióla idea original, formulación y revisión del proyecto. JYY ha participado en la formulación y revisión del proyecto. RSM, ARC, ACQ, MLB, MHS participaron en la redacción del proyecto, recolección de muestras y desarrollo experimental. AFL y DLL participaron en el desarrollo experimental, análisis de resultados, discusión y revisión crítica. RSM, JYY, ARC, ACQ, MLB, MHS, MGP y PMC participaron en la concepción del artículo, análisis de resultados, redacción de estos, discusión, revisión crítica y evaluación de la versión final del manuscrito. Todos los autores aprueban la versión final del artículo.

Financiamiento: La investigación fue financiada por la Escuela Profesional de Medicina Humana de la Facultad de Ciencias de la Salud de la Universidad Peruana Unión.

Conflicto de interés: Los autores declaran no tener conflictos de interés en la publicación de este artículo. 


\section{REFERENCIAS BIBLIOGRÁFICAS}

1. Mouiche MMM, Moffo F, Akoachere J-FTK, Okah-Nnane NH, Mapiefou NP, Ndze VN, et al. Antimicrobial resistance from a one health perspective in Cameroon: a systematic review and meta-analysis. BMC Public Health. 2019;19(1):1135. doi:10.1186/s12889-019-7450-5.

2. Chitnis V, Chitnis D, Patil S, Kant R. Hospital effluent: A source of multiple drug-resistant bacteria. Current Science. 2000;79(7):989-991.

3. Tahrani L, Soufi L, Mehri I, Najjari A, Hassan A, Van Loco J, et al. Isolation and characterization of antibiotic-resistant bacteria from pharmaceutical industrial wastewaters. Microb Pathog. 2015;89:54-61. doi: 10.1016/j.micpath.2015.09.001.

4. Paulshus E, Kühn I, Möllby R, Colque P, O'Sullivan K, Midtvedt T, et al. Diversity and antibiotic resistance among Escherichia coli populations in hospital and community wastewater compared to wastewater at the receiving urban treatment plant. Water Res. 2019;161:232-241. doi: 10.1016/j.watres.2019.05.102.

5. Khan NA, Ahmed S, Vambol S, Vambol V, Farooqi IH. Field hospital wastewater treatment scenario. Ecol Quest. 2019;30(3):57-69. doi:10.12775/EQ.2019.022.

6. Ministerio del Ambiente [Internet]. Lima: MINAM; 2021 [citado el 15 de marzo de 2021]. MINAM se une al MINSA en inauguración de Planta de Tratamiento de Residuos Sólidos Hospitalarios. Disponible en: https://www.minam.gob.pe/notas-de-prensa/ minam-se-une-al-minsa-en-inauguracion-de-planta-de-tratamiento-de-residuos-solidos-hospitalarios/.

7. Dickin SK, Schuster-Wallace CJ, Qadir M, Pizzacalla K. A Review of Health Risks and Pathways for Exposure to Wastewater Use in Agriculture. Environ Health Perspect. 2016;124(7):900-909. doi:10.1289/ ehp.1509995.

8. Hospital de Huaycán [Internet]. Lima: Hospital de Huaycan; 2021. Indicadores de gestión Hospital de Huaycán [citado el 15 de marzo de 2021]. Disponible en: http://www.hospitalhuaycan.gob.pe/estadistica/ section.php?id=1.1.0.0\&active $=$ here\&ide $=11$.

9. Hospital Nacional Hipólito Unanue [Internet]. Lima: HNHH; 2021. Estadísticas 2019 [citado el 15 de marzo de 2021]. Disponible en: http://www.hnhu.gob.pe/Inicio/oficina-de-estadistica/estadisticas/ estadistica-2019/.

10. CHROMagarTM mSuperCARBATM. Instrucciones de uso, NTEXT-089 V5.0. [citado el 15 de marzo de 2021]. Disponible en: http:// www.chromagar.com/clinical-microbiology-chromagar-msupercarba-cre-epidemiologic-issues-76.html.
11. Clinical \& Laboratory Standards Institute. M100: Performance Standards for Antimicrobial Susceptibility Testing, 30th Edition. Clinical \& Laboratory Standards Institute. [citado el 15 de marzo de 2021]. Disponible en: https://clsi.org/standards/products/microbiology/documents/m100/.

12. Jiménez Pearson MA, Galas M, Corso A, Hormazábal JC, Duarte Valderrama C, Salgado Marcano N, et al. Consenso latinoamericano para definir, categorizar y notificar patógenos multirresistentes, con resistencia extendida o panresistentes. Rev Panam Salud Publica. 2019;43:e65. doi: https://doi.org/10.26633/RPSP.2019.65.

13. InnuPREP Bacteria DNA Kit [citado el 15 de marzo de 2021]. Disponible en: https://www.analytik-jena.com/products/kits-assays-reagents/kits-for-dnarna-extraction/innuprep-bacteria-dna-kit/.

14. Kiratisin P, Apisarnthanarak A, Laesripa C, Saifon P. Molecular characterization and epidemiology of extended-spectrum-beta-lactamase-producing Escherichia coli and Klebsiella pneumoniae isolates causing health care-associated infection in Thailand, where the CTX-M family is endemic. Antimicrob Agents Chemother. 2008;52(8):2818-2824. doi: 10.1128/AAC.00171-08.

15. Sacsaquispe-Contreras R, Bailón-Calderón H. Identificación de genes de resistencia a carbapenémicos en enterobacterias de hospitales de Perú, 2013-2017. Revista Peruana de Medicina Experimental y Salud Pública. 2018;35(2):259-264. doi: 10.17843/rpmesp.2018.352.3829.

16. Zagui GS, de Andrade LN, Moreira NC, Silva TV, Machado GP, da Costa Darini AL, et al. Gram-negative bacteria carrying $\beta$-lactamase encoding genes in hospital and urban wastewater in Brazil. Environ Monit Assess. 2020;192(6):376. doi: 10.1007/s10661-020-08319-w.

17. Zhang L, Ma X, Luo L, Hu N, Duan J, Tang Z, et al. The Prevalence and Characterization of Extended-Spectrum $\beta$-Lactamase- and Carbapenemase-Producing Bacteria from Hospital Sewage, Treated Effluents and Receiving Rivers. Int J Environ Res Public Health. 2020;17(4). doi: 10.3390/ijerph17041183.

18. Zurfluh K, Bagutti C, Brodmann P, Alt M, Schulze J, Fanning S, et al. Wastewater is a reservoir for clinically relevant carbapenemase- and 16s rRNA methylase-producing Enterobacteriaceae. Int J Antimicrob Agents. 2017;50(3):436-440. doi: 10.1016/j.ijantimicag.2017.04.017.

19. Hospital Nacional Hipólito Unanue [Internet]. Lima: HNHH; 2021. Historia [citado el 15 de marzo de 2021]. Disponible en: http://www. hnhu.gob.pe/Inicio/historia/.

20. Gutiérrez R, Hidalgo L, De La Cruz L. Análisis Situacional de Salud del Hospital de Huaycan-2019. Lima: Hospital de Huaycán; 2019. 